\title{
17. Epilogue: rules for reformers
}

\author{
Paul 't Hart
}

\section{From imperatives to lessons}

There is a widespread need for adaptation, change and even 'paradigm shifts' in the way societies are governed and how their governments organise themselves. Many contributions to this volume highlight this need. Let us look at some of the main drivers.

Citizens, companies and governments everywhere are, first of all, trying to come to terms with the true implications of the information age. The boardroom and street-level consequences of life in the information society are challenging the system-level architecture of governance. Technologically driven possibilities and culturally embedded expectations now demand that governments follow corporations and engage in mass customisation-responsive, real-time and holistic service delivery. An example in Australia is the 'Government 2.0 Taskforce' focused specifically on the implications of the digital revolution for government. Its clarion call for reform is loud and clear: 'Leadership and policy and governance changes are needed to: shift public sector culture and practice to make government information more accessible and usable; make government more consultative, participatory and transparent; build a culture of online innovation within Government; and promote collaboration across agencies' (<http://gov2.net.au/report/>). The drivers of this development are not going to go away, and governments that lag behind in adapting to them effectively diminish their country's or region's international competitiveness and quality of life.

In addition, governments are called on to adapt to an age in which their public authority has become more dependent than ever upon their capacity to 'deliver'. As predicted a century ago by German sociologist Max Weber (1978), contemporary society is one in which tradition, mysticism and even charisma simply do not cut it as foundational principles for state power and legitimacy. Democratic mandates today are more conditional and fleeting than ever before. We live in the age of value for money. In a value-for-money environment, citizens take the rule of law and the democratic authenticity of the state largely for granted (ignoring their fundamental value and precariousness). Instead, they judge their rulers on their perceived contribution to their own prosperity and wellbeing. Public leadership in such a world becomes entirely transactional. 
Citizens pay taxes, vote in legislatures, and, mostly, obey the law. They are perfectly willing to do all that, as long as they feel their efforts are met by governments keeping their part of the bargain: providing safety, prosperity, care, sustainability and all the many other things they say they will. In a value-formoney society, we judge government first and foremost by its results. In a world of unprecedented technological change, fierce global economic competition, demographic shifts, ecosystem imbalances and socio-cultural transformation, governments can 'deliver' such results only if they manage to achieve ongoing institutional reforms and societal learning processes.

A third major driver of reform I want to single out is the inexorable rise of resilience considerations in public policy and administration. The end of the Cold War has not heralded the kind of benign, Western-led, democratic new world order that former US President George H. W. Bush foresaw. Instead, we have a geopolitical disequilibrium, small wars, refugee flows and mass-casualty terrorism. This new reality has combined with the growing awareness of climate change and the occurrence of a series of natural and human-made catastrophes to teach Western governments that the ever-growing complexity and transnational interconnectedness of the economic and infrastructural systems that sustain our way of life constitute a two-edged sword. They make us richer but not necessarily safer. If risk is a product of the impact and the probability of harmful events then the news is not great on both fronts. Relatively small mishaps in vital systems can cascade quickly and widely throughout and across societies; at the same time, a changing climate as well as a more conflict-ridden world are more likely to throw up significant disruptions. The changing risk matrix they face requires contemporary societies to be agile and resilient in the face of rude surprises. In many cases, this requires deep reforms that far transcend technical tinkering with emergency plans.

This volume has brought together insightful accounts of past and ongoing public-policy reform efforts designed to meet some of these adaptive challenges. These accounts have been written by some of Australia's and New Zealand's most respected reform architects, advocates and observers, as well as by the American policy scholar Eric Patashnik. It was his landmark study Reforms at Risk (Patashnik 2008) that provided the main intellectual impetus for organising the conference on which this volume is based. With so much expertise and analysis bundled in the one volume, I felt it would be worth trying to distil the common lessons that can be drawn from what effectively are decades of recent and ongoing reform experiences across a range of policy sectors in three countries. Rather than doing so in the form of a typical academic piece full of complexity, contingency and provisos, I will throw the usual academic caution to the wind and jump into prescription. 
What follows is unabashed advice and exhortation addressed to a hypothetical 'leader' within or outside government who finds him or herself in the middle of a policy sector in which 'reform' is on the agenda. What, on the basis of this volume, should they 'need to know' about the challenges involved in developing and entrenching reform in the public sector? What, in other words, are the 'rules of reform' that reform proponents (and indeed opponents) can ignore only at their peril?

\section{Rules for reading the context of reform}

\section{No pain, no reform}

Do not expect to gain traction on reforms when most people feel the status quo is not so bad at all. When you do, the perceived costs of reform-uncertainty, adjustment, enforcement - can all too easily be construed by your opponents as not being worth the potential gains. Tackling complacency comes before everything else. Raise the public salience of change by demonstrating how intolerable present arrangements and practices really are. Give ample voice to those who feel the pain of the present and to those who can communicate authoritatively what future pain will result in the absence of reforms.

\section{Do not let a 'good' crisis go to waste}

Avoid the temptation to switch to reactive, defensive, firefighting mode when a major, unexpected 'shock to the system' - a major incident, a damning set of numbers, a media feeding frenzy, a geopolitical surprise-presents itself on your watch. History rewards those who have the capability to understand and interpret the crisis of the day to underpin hitherto infeasible attitude and policy changes. Be prepared to err on the risk of exaggeration in (re)framing crises if the strategic opportunities for breaking existing policy deadlocks they present are worth it. 'Turning up the heat' is a sine qua non of reformist leadership, and unscheduled adversity provides a rare opportunity to do so without overspending your political capital.

\section{Have your bottom drawer well stocked}

When a sense of crisis takes hold and discredits the legitimacy of the status quo, the public is ripe for new ideas that hold the promise of moving them towards a better future. But the pressure-cooker of crisis management is hardly the time to start thinking up such ideas - that needs to have been done 
beforehand. You need to invest in an ongoing brains trust doing regular 'whatif' exercises, scenario development and strategic contingency planning. This helps you provide the intellectual leadership when the time is ripe. And having a few concrete, symbolically significant and readily implementable designs for programs and projects does not hurt either. Crises concentrate the mind, free up money and reduce procedural barriers - and you had better be ready for them when they occur.

\section{Rules for making reforms happen}

\section{Use the 'R' word judiciously}

History tends to look most kindly on reforming leaders - those who are credited with the transformation of old orders into new ones. The growing awareness of this reality has led to every government and every minister compulsively talking up their reformist credentials. Reform has become, in other words, a political must for leaders. No self-respecting new CEO can afford not to announce grand plans for reorganisation; no self-respecting government can avoid employing the rhetoric of reform. The risk is that even the most timid, technical and trivial policy changes are talked up as 'reforms'. This gives reform a bad name.

The term 'reform' ought to be reserved for methodical attempts to achieve farreaching changes in key beliefs and behaviours within a community and the governance structures underpinning them. Marginal adjustment of existing practices - however defensible - is not reform; it is public policy as usual. To oversell it as reform sets you up as an emperor who has no clothes.

When you feel that the time for needed reform is simply not ripe in your sector or organisation (for example, because the power of the status-quo players arguing that things 'ain't broken' is momentarily too entrenched), content yourself with trying to create that ripeness by trying to rub people's noses in the reality of the problems they (ought to) face rather than prematurely selling them ready-made 'reforms' as solutions for those problems. Whatever you do, concentrate your rhetoric of reform on a limited number of areas where you feel not just the need but also the sense of urgency for significant change are most palpable.

\section{Prepare to be unloved}

Reforms that have only winners all of the time are few and far between. If things were that beneficial, they would already have been adopted a long time ago. True reforms have redistributive effects. They shake up the status quo. They will therefore be opposed by those who benefit from that status quo, as well as 
by people who are fooled into thinking they benefit from it. You do not have to go as far as to fully embrace Machiavelli's assertion that it is better for a ruler to be feared than loved. But you still need to be prepared for pushbackanticipate it, wear it gracefully but resolutely, and most of all find ways to keep talking meaningfully to reform opponents.

\section{Reform zeal without analysis is bound to end in tears}

Never forget that the burden of proof is always on the reformer; you need to be able and willing to articulate the implicit theory of behavioural change that underpins your reform vision (and encourage it to be tested as much as possible before it is put into wholesale practice). If you do not have the killing arguments, do not expect to be able to persuade anyone. And if you do not have the power to persuade, do not expect to make reform happen by brutal imposition in any except the direst circumstances (for example, war and violent conflict, acute fiscal crisis, systemic breakdowns, popular revolts). Kevin Rudd learned this the hard way; he failed to persuade on climate change and he failed even to try to persuade on the resource super profits tax. Crucial to the power to persuade are impeccable analysis and compelling narratives. Let us look at each of them in turn.

\section{Holistic analysis rather than expert monopolies}

Too often reformers focus their mental energy on bolstering their preferred interventions in one particular area instead of methodically working through how they stem from and will impact upon the larger system in which they are embedded. This gets you nowhere.

Developing truly 'killing' reform arguments requires an investment in holistic analysis - in particular, in systems thinking. You need to know the system that you propose to reform inside and out - all of it, not just a particular part of it. Water reform cannot succeed without a systemic analysis of natural-resources management. Traffic congestion cannot be tackled without a systemic analysis of urbanisation. Hospital reform cannot succeed without a systemic analysis of public health.

And you should never forget that key knowledge of the intricacies of any system does not reside exclusively at the top or within government. The task of underpinning reforms cannot be left to government economists, lawyers and technical specialists just because the Public Service happens to be full of them. Your role is to make sure that the expertise of multiple professions, government insiders and outsiders, and strategic thinkers is brought to bear in a rigorous fashion. 


\section{Every reform needs a compelling narrative}

Killing arguments require more than just sound analysis. They also require an investment in public communication: your language, your timing and your performances. A compelling narrative is essential in 'selling' the reform to the mainstream of uncommitted 'wait-and-see' public servants and stakeholders out there to have a guiding narrative to help them literally 'make sense' of what is going on. This is not about spin; it is about building a public case designed to make people face the need for major change.

Too often reformers get caught up in arcane policy detail and forget that the ultimate source of authority and momentum lies with the populace, not the community of technocratic sectoral insiders. In the absence of a compelling narrative, a reform effort misses the chance of making a significant discursive impact; it will not change the language in which we think and talk about ourselves and the challenges we face. That is a missed opportunity, as discursive interventions cost little yet can have great effects.

Most importantly, a coherent narrative delivered in a compelling fashion can give people reasons to believe in the process and the changes they are expected to make in their thinking, rules and practices. Bob Hawke and Paul Keating won most of their reform battles because, between them, they covered a wide spectrum of persuasive skills and target audiences, and experimented with a range of persuasive formats (including well-orchestrated stakeholder 'summits'). Rudd and Penny Wong failed to get traction on the carbon pollution reduction scheme (CPRS) not just because of the machinations within the Liberal Party but first and foremost because they could sing only one, fairly incomprehensible ('CPRS') reform tune, which a large part of the Australian public simply did not 'get'.

\section{Leading from the front is not your only option}

The Lange-Douglas reform episode in New Zealand is a classic example of a 'heroic' reform style (Goldfinch 2000). They went out there, argued the case, got the numbers, and took the plunge. Though appealing to romantic ideals of 'true leadership', this style works only when the number of decisional forums and the number of veto players in each of them are comparatively small. When that number is larger - as tends to be the case in the post-mixed-member proportional representation world of coalition bargaining in New Zealand politics, the COAG world of federal-state relations, and the hyper-complex world of global trade and climate governance - barging in through the front door just does not work. Patient coalition building does. 
Though both Hawke and Keating entertained über-romantic visions of themselves as strong leaders, they were smart enough to realise that the kind of economic transformation of Australia they envisaged would not work without coopting organised labour and, to some extent, the big end of town into codetermining the pace and shape of the reform process. Backstage diplomacy is as vital - and often even more vital - in building support for reforms as front-stage dramaturgy. To use a military analogy: the wars to reduce smoking and make Victoria's roads the safest in the country described in this volume were not won by public-sector equivalents of the charismatic general of the Montgomery and Patton kind; they were won by persistent coalition building in the Eisenhower and Marshall mould.

\section{Grand plans are not the only way to package reform}

Grand ambitions do not necessarily require a 'crash, or crash through' approach to achieve all targets in one fell swoop. In fact, the big-bang approach can create such levels of uncertainty, fear and resistance that it can be its own undoingas Gough Whitlam found out at fatal cost. Even Roger Douglas - hardly a patsy when it came to taking political risks in the service of reform-sometimes used salami tactics and patience to work through sticky points during lengthy deliberations. Grand designs are always high on lofty but abstract promises yet low on specifics and therefore prone to peter out in implementation. Those grand reforms that are more concrete - such as Jeff Kennett's privatisation agenda in Victoria in the early 1990s, or the Al Gore-led 'reinventing government' operations in the US federal bureaucracy under Bill Clinton-also invite big opposition. Kennett fought his way through, but more often than not, political sponsors are jittery when it comes to spending political capital on grand reforms that run into headwinds. They need it more badly on the big-ticket substantive policy struggles of the day. Or they simply lose interest when they realise that there are no votes in the reforms that are on the table.

When political backing is sporadic and inconsistent, a piecemeal, seemingly technical reform approach is not such a bad choice. It allows for proceeding much more unobtrusively and therefore less controversially. Charles Lindblomcited by various of our experts in this volume - was fundamentally right that small, mutually reinforcing changes when maintained and accumulated over a period can get you a long way away from the status quo. His ploy-smuggling in successive incremental change - fits the reality of public policy making in democratic systems a lot better than the raw energy of Whitlamesque 'programs' and 'duumvirates', which inevitably entice reformers to try too much too soon. 


\section{Engage widely early on}

Reformers always face the temptation to keep the circle of those in the know as small as possible. This temptation should be resisted. Do not succumb to the 'groupthink' that results from talking only to fellow reform proponents (or opponents, as the case might be). It sets you up for unpleasant surprises: badly vetted ideas, unexpected opposition, and implementation problems. Widening the circle and broadening the substance of the conversation are generally good ideas; in case of doubt, err on the side of inclusiveness. It is simply foolish not to bring to the design table the groups whose position and behaviour are to change as a result of the reform.

It is equally foolish not to benefit from the practical experience of those who will be implementing the reforms, both inside and outside the public service. You should, moreover, bring those actors to the table at a time and in a manner that they can still have a significant impact on the framing of key reform parameters. Expecting them to turn up to essentially swallow proposals precooked by a tightly held inner circle is naive and most likely counterproductive.

Yes, engaging widely even at the early stage of reform design will increase the transaction costs of the design process. Getting more and more diverse stakeholders to the table and nudging them towards agreement can be time consuming and energy sapping. These discussions are not love-ins. They can be tough and painful as well as creative and empowering. But more often than not the costs of collaborative design are a good price to pay for what you get: more robust proposals and the all-important buy-in from those whose collaboration is essential in making reforms work.

\section{Create reform packages and bandwagons}

It is astounding how often reformers forget some basic principles of negotiation and bargaining. One such principle is that of enlarging the pie. Research in this area finds time and again that people will fight to the hilt over individual issues but are more often than not able to reach agreements over creatively designed broader reform packages (bundling up a range of issues and areas) or bandwagons (where short-term costs for actors are offset by the certainty of longer-term gains on subsequent reform moves in the same area). This is especially so when they have been able to take part in the very scoping and framing of those packages and bandwagons.

Whatever you might think of the European Union's policies and pitfalls, it has been an astounding saga of cascading institutional reform against all odds. In just a few decades, its architects and entrepreneurs have been able to extend its depth (the degree of delegation of state sovereignty granted to EU-level 
institutions), scope (the range of policy areas covered) and membership. Creating bandwagons and packages to overcome impasse and circumvent veto power has been vital to this success every step of the way. They are the best possible ways of sharing the gains as well as splitting and trading the pains of reform.

\section{Rules for making reforms stick}

\section{A minimum winning coalition is not good enough}

Few if any contemporary democracies are constitutionally wired in the way New Zealand was during its last great reform period of 1984-90. The name of most public-policy games is dispersed power, not executive dominance. Reformers who think they can simply impose big changes once they are adopted in cabinets or legislatures will find themselves forced into humiliating backdowns and u-turns. Reformers who rely on the smallest of possible coalitions and ignore the other 49 per cent set themselves up for relentless rearguard battles during implementation and quite likely for outright policy reversals once they lose the power to impose.

The long-term viability of reforms is greatly enhanced when the coalition that is carrying it is 'oversized'. If this can be achieved only at the price of some of the ideological purity of the original reform philosophy then so be it. You will need the broad support base to withstand the forces of reaction that will seek to undermine the reform process. You will need to embed the reform momentum as widely as possible within the government bureaucracy-pivotally including the central agencies - so as to make its memory, diligence and paradoxically its inertia work for rather than against the integrity and continuity of already enacted reforms.

\section{Just because they are big achievements does not mean reforms succeed}

Therefore, winning the battle to get them designed and adopted is a necessary but not a sufficient step to make reforms work and to make them last. Reforms are wars not battles. When you do not attend to their implementation and long-term maintenance, do not expect them to deliver the goods. When their implementation is ill designed and under managed, their negative unintended consequences end up dwarfing those that were aimed and planned for. Wellintended reforms can easily end up looking like 'fatal remedies' (Gillon 2000; Sieber 1981). Reform opponents seize their chance to fight back, sabotage and twist the process of putting intentions into action. 
It is hard to find reforms that are reversed as soon as the political tide has turned, and there are plenty of reforms that suffer from what Patashnik in his book labels 'death by a thousand cuts': while nominally still in force, their force and integrity are undermined by lobbying from special interests, resulting in watered-down implementation or legislative emasculation. What goes for public policy in general applies even more so for high-stakes reforms; as a proponent, you cannot rest on your laurels once the bill has become the law. You have to be in it for the long haul. You need to be as equally attentive, inventive and tenacious in the implementation and consolidation phases as you are in the design and adoption processes.

\section{Incorporate mechanisms that make reforms self- sustaining}

It is important to think about why citizens and stakeholders change their behaviour as a result of the implementation of a reform. You need to understand that basic carrots and sticks buy only opportunistic compliance that is costly to keep bankrolling and policing. Sometimes there is no other way-for example, in industrial relations and health and safety, where employers will always be tempted to engage in races to the bottom given the relentless pressures on them to raise productivity (by reducing costs).

Yet the most robust reforms are truly transformative. They change people's norms and values. Once new standards of appropriateness have been internalised and disseminated widely, compliance costs tumble, and so does the risk of reform erosion or reversal. Child labour is now considered to be simply unacceptable in countries such as New Zealand and Australia. Smoking is now firmly socially stigmatised (though pivotally not made illegal). Drink-driving is getting there, though there is a way to go.

These ideational changes have not happened by accident. As Patashnik's study as well as some of the case studies in this book show, they are the product of clever reform designs that have managed to create behavioural incentives that get into people's heads and hearts. If you are serious about protecting the longterm integrity of reforms, this is the way to go. It is about cleverly combining the logic of economics (as Keating learned long ago from his political mentor Jack Lang: bet on self-interest because at least it is always trying) with the logic of behavioural research in psychology, sociology and communication studies (teaching us to bet on the subconscious and social drivers of human perception, identity, judgment and preference formation). Thaler and Sunstein's rightly best-selling book Nudge (2008) is a good place to start if you are serious about this ambition. Sunstein was subsequently appointed Barack Obama's regulation tsar, so do not think it is just two eggheads talking. 


\section{Afterword}

This 'memo' has summed up what I think our current knowledge about reforms allows us to convey to reformers and stakeholders in reform processes. It is up to them to explore how they can make some or ideally all of these lessons work for them. This will no doubt include exploring the potential tensions between these various imperatives. After all, the craft of reformist leadership is an art, not a science. The rules of experience provided above do not make a cookbook, nor could such a book ever be written. In most instances, there are multiple potentially passable paths to reform. There will always remain a need for situation-specific judgments and intuitions about the what, when and how of going down one or the other road - and when to reassess that choice.

To inform those judgments as well as possible, however, it is important that institutions such as ANZSOG keep documenting the experiences and views of those who have already travelled the road of reform, and that public-policy academics in Australia and New Zealand step up their efforts to conduct the methodical, comparative and longitudinal research into reform dynamics that is essential to putting these practitioner tales into a broader perspective. To begin with, ANZSOG should make it part of its mission to hold a major 'learning from experience and research' conference on public-sector reform every five years to create a platform where both types of insights can be aired, compared and bundled up.

\section{References}

Gillon, S. M. 2000, 'That's Not What We Meant To Do': Reform and its unintended consequences in twentieth century America, W. \& W. Norton, New York.

Goldfinch, S. 2000, Remaking New Zealand and Australian Economic Policy: Ideas, institutions and policy communities, Victoria University Press, Wellington.

Patashnik, E. 2008, Reforms at Risk, Princeton University Press, Princeton, NJ.

Sieber, S. D. 1981, Fatal Remedies: The ironies of social intervention, Plenum Press, New York.

Thaler, R. and Sunstein, C. 2008, Nudge: Improving decisions about health, wealth, and happiness, Yale University Press, New Haven, Conn.

Weber, M. 1978, Economy and Society: An outline of interpretive sociology, University of California Press, Berkeley. 